\title{
ANALISIS ALOKASI PENGGUNAAN FAKTOR-FAKTOR PRODUKSI DALAM UPAYA PENGEMBANGAN AGRIBISNIS LIDAH BUAYA DI KOTA PONTIANAK
}

\author{
MULYADI SAFWAN' ${ }^{1)}$, ANI MUANI', ADI SUYATNO ${ }^{2)}$ \\ 1) Alumni Magister Manajemen Agribisnis Fakultas Pertanian \\ Universitas Tanjungpura Pontianak \\ ${ }^{2)}$ Staf Pengajar Fakultas Pertanian Universitas Tanjungpura Pontianak \\ mulyadikemayant@gmail.com
}

\begin{abstract}
This research to be held at North Pontianak district of Pontianak City, used survey method. The aimed of the research are knews to analysis the impact of production factors to the total product and to analysis of the effisiensy using of the production factors Aloe vera farming in the Pontianak City. Colecting the primery data to the all responden as total 43 . To analys of the used production factors by function of Cobbs-Douglas production estimates with change in linier function. To knows the impact all of variables independent $(\mathrm{Xi})$ versus variable dependent (Y), used F Test in $95 \%$ significantly and the impact are independent variables (Xi) to variable dependent $(\mathrm{Y})$ used t Test. Effisiency to the production factors used to be analysed by allocative efficiency and use product marginal ratio value similarly with the input cost. The result of the research saw the impact factors of the production seedling, dust, urea are higly significant, exept the labour factor is not significant to the Aloe vera production at center production north Pontianak district of the Pontianak City. The result of the allocative efficiency analysis saw that using the input production seedling, dust and urea in Aloe vera farming are not efficient yet, so need add the input to got allocative efficiency. But labour as an input production is not efficient, and must be lessened to get allocative efficiency. The result of Allocative efficiency economic analysis can be used as adjustment to improve the Aloe vera agribisnis system in Pontianak City.

Keywords : Aloe vera. L, centre of production, allocative efficiency, agribisnis
\end{abstract}

\section{PENDAHULUAN}

Sebagai negara agraris, Indonesia memiliki potensi besar untuk mengembangkan usaha agribisnis ditengah era globalisasi saat ini. Kebijakan perekonomian nasional yang mendukung perkembangan ekspor terutama ekspor non-migas telah ditindak lanjuti oleh Pemerintah Provinsi Kalimantan Barat melalui pengembangan produk pertanian yang mempunyai keunggulan komperatif yaitu tanaman lidah buaya dan telah dijadikan tanaman unggulan daerah sesuai surat keputusan Gubernur Kepala Daerah Provinsi Kalimantan Barat Nomor 505 Tahun 2002, tentang penetapan komoditi unggulan daerah Kalimantan Barat untuk sektor pertanian. Berdasarkan Surat Keputusan Gubernur Provinsi Kalimantan Barat tersebut ditetapkan beberapa komoditi unggulan untuk sektor pertanian dan salah satu komoditi yang ditetapkan sebagai komoditi unggulan adalah tanaman lidah buaya (Aloe vera.L). Di Kota Pontianak tanaman lidah buaya telah dibudidayakan oleh masyarakat sejak tahun 1980 namun secara komersil baru sekitar1990 dan ditanam di lahan gambut (Anonim, 
2010). Luas lahan gambut di Kalimantan Barat mencapai 1.729.980 hektar atau $29,99 \%$ dari total jumlah lahan gambut Kalimantan seluas 5.769.246 hektar(Anonim 2004) dan sangat prospektif untuk pengembangan agribisnis buaya. Perkembangan lidah buaya yang cukup pesat di Pontianak terjadi pada tahun 2004 dimana produksi mencapai lebih dari 26.000 ton/tahun dengan luas areal tanam mencapai 161 hektar serta luas panen mencapai 137 hektar. Selanjutnya produksi terus menurun dilkuti dengan penurunan luas tanam, sehingga berdasarkan data produksi lidah buaya di Kota Pontianak pada tahun 2009 tinggal hanya 1.512 ton dengan luas tanam sekitar 38 hektar dan luas panen hanya 35 hektar, jauh menurun jika dibandingkan pada tahun 2004 dengan produksi 26.304 ton dan luas tanam 137 hektar (UPTD Terminal Agribisnis Badan Ketahanan Pangan Kota Pontianak, 2013).

Ditinjau dari segi kualitas dan produktifitas, lidah buaya yang dibudidayakan oleh masyarakat Kota pontianak, termasuk yang terunggul di Indonesia dan diakui keunggulannya di dunia(Sulaeman. S, 2007). Berbeda dengan tanaman lidah buaya yang di budidayakan di luar Pontianak, seperti Amerika dan Cina, setiap pelepahnya memiliki berat hanya $0,5-0,6 \mathrm{~kg}$ dan di panen hanya 1 kali setahun karena kendala musim dingin. Di daerah Bogor, produksi pelepah lidah buaya yang dihasilkan oleh petani sebagian besar pada mutu kelas B dengan berat 0,4 - 0,6 kg (Ahdhiana,2005). Bila ditelaah dari segi agribisnis, lidah buaya merupakan komoditi yang sudah lama diperdagangkan dan sudah dikenal oleh negara-negara maju seperti Amerika Serikat, negara-negra Eropa, Cina, Jepang, Taiwan, Korea, India, Australia, dan negara-negara di Afrika sebagai taman obat. Kenyataan ini akan semakin meningkatkan status komoditi lidah buaya menjadi barang ekonomi bernilai tinggi sehingga memperluas ruang agribisnis, Ahmad, S, M.A, Kalhoro, Z. Kalpadia, Y. Badar(2003).

Adanya komoditas unggulan tanaman lidah buaya yang dapat tumbuh dengan baik pada lahan gambut yang cukup luas terdapat di wilayah provinsi Kalimantan Barat diharapkan dapat pula berkontribusi terhadap peningkatan pendapatan asli daerah (PAD). Oleh karena itu agribisnis lidah buaya di Kalimantan Barat ini, khususnya di sentra produksi perlu direvitalisasi agar di peroleh manfaat yang lebih baik lagi walaupun luas tanam dan produksi saat ini jauh menurun jika dibandingkan pada tahun 2004. Menurunnya produksi dan luas lahan tanam lidah buaya seperti tersebut diatas diperkirakan terjadi akibat alokasi penggunaan faktor-faktor produksi yang belum efisien sehingga berpengaruh terhadap agribisnis. Gejala penggunaan faktor faktor produksi yang belum efisien ditunjukan oleh produktifitas usahatani lidah buaya yang masih relatif rendah dan bervariasi setiap tahun, bahkan pada tahun 2011 dan 2012 pada posisi luas panen yang sama yaitu masing-masing 46 hektar namun produktifitas berbeda yaitu tahun 2011 hanya 51 kwintal dan 2012 menjadi 58 kwintal. Oleh sebab itu perlu dilakukan penelitian berjudul "Analisis Alokasi Penggunaan Faktor-Faktor Produksi dalam Upaya Pengembangan Agribisnis Lidah Buaya di Kota Pontianak".

\section{METODE PENELITIAN}

Penelitian ini menggunakan metode survei yang bersifat deskriptif asosiatif yaitu suatu metode untuk mengetahui hubungan dua variabel atau lebih atau hubungan variabel bebas dan variabel terikat (Iskandar, 2008). Lokasi 
penelitian di Sentra Produksi Lidah Buaya Kecamatan Pontianak Utara Kota Pontianak Kalimantan Barat. Pemilihan lokasi penelitian ditentukan secara sengaja (purposive) dengan pertimbangan lokasi-lokasi tersebut merupakan daerah sentra produksi lidah buaya di Provinsi Kalimantan Barat dan petani masih aktif melakukan kegiatan usahatani lidah buaya. Penelitian dilaksanakan selama enam bulan dimulai penyusunan proposal penelitian sampai dengan penyelesaian penyusunan tesis (Januari hingga Juni 2014). Selanjutnya objek dalam penelitian ini adalah petani lidah buaya yang masih aktif melaksanakan usahatani lidah buaya (Aloe vera.L) di sentra produksi lidah buaya Kecamatan Pontianak Utara Kota Pontianak Provinsi Kalimantan Barat. Untuk memperoleh dan mengolah data penelitian diperlukan peralatan meliputi ; (1) kuesioner, (2) alat tulis menulis, (3) kalkulator, (4) komputer/software Program SPSS Versi 18, (5) kamera, dan (6) peralatan lain yang diperlukan.

Alat untuk menganalisis data faktor-faktor produksi yang berpengaruh terhadap produksi lidah buaya digunakan model fungsi Produksi Cobb-Douglas yang ditransformasikan ke dalam bentuk double logaritma natural (ln), sehingga merupakan bentuk linear berganda sebagai berikut (Soekartawi, 1994) :

$$
\begin{aligned}
\ln \mathrm{Y}= & \ln \mathrm{A}+\alpha_{1} \ln \mathrm{X}_{1}+\alpha_{2} \ln \mathrm{X}_{2}+\alpha_{3} \ln \mathrm{X}_{3}+\alpha_{4} \ln \mathrm{X}_{4}+\alpha_{5} \ln \mathrm{X}_{5}+\alpha_{6} \ln \mathrm{X}_{6} \beta 1 \ln \mathrm{Z}_{1} \\
& +\beta_{2} \ln \mathrm{Z}_{2}+\partial_{1} \ln D_{1}+
\end{aligned}
$$

Keterangan :

$$
\begin{aligned}
\ln Y & : \text { Produksi Lidah Buaya }(\mathrm{kg}) \\
\mathrm{A} & : \text { Intersep } \\
\mathrm{X}_{1} & : \text { Luas lahan }(\mathrm{Ha}) \\
\mathrm{X}_{2} & : \text { Tenaga kerja }(\mathrm{HOK}) \\
\mathrm{X}_{3} & : \text { Bibit }(\mathrm{Btg}) \\
\mathrm{X}_{4} & : \text { Pupuk Urea }(\mathrm{kg}) \\
\mathrm{X}_{5} & : \text { Abu (kg) } \\
\mathrm{X}_{6} & : \text { Pestisida (ltr) }
\end{aligned}
$$

Analisis dan pengolahan data fungsi keuntungan Cobb-Douglas dilakukan dengan bantuan software program SPSS versi 18. Dari hasil analisis fungsi produksi Cobb-Douglas dalam bentuk linear berganda didapat besarnya koefisien determinasi $\left(\mathrm{R}^{2}\right)$, nilai $\mathrm{F}_{\text {hitung }}$, dan $\mathrm{t}_{\text {hitung. }}$.

Efisiensi penggunaan faktor-faktor produksi dianalisis menggunakan efisiensi alokatif atau efisiensi harga. Untuk menganalisis apakah penggunaan faktor-faktor produksi telah mencapai efisiensi alokasi, digunakan rasio antara nilai produk marginal dengan harga masing-masing faktor produksi dengan rumus sebagai berikut (Soekartawi, 1994).

$$
N P M x i=P x i \quad \text { atau } \quad \frac{N P M x i}{P x i}=1
$$

Keterangan :

$$
\begin{array}{ll}
\mathrm{NPMx}_{\mathrm{i}} & \text { : Nilai Produk Marginal untuk faktor produksi Xi } \\
\mathrm{Px}_{\mathrm{i}} & \text { : Harga faktor produksi Xi }
\end{array}
$$


Dalam kenyataanya NPMx tidak selalu sama dengan Px, yang sering terjadi adalah :

$\mathrm{NPMx}_{\mathrm{i}} / \mathrm{Px}_{\mathrm{i}}=1$ : berarti penggunaan input produksi $\mathrm{X}$ efisien

$\mathrm{NPMx}_{\mathrm{i}} / \mathrm{Px}_{\mathrm{i}} 1$ : berarti penggunaan input produksi $\mathrm{X}$ belum efisiensi, untuk mencapai efisien input $\mathrm{X}$ perlu ditamah.

$\mathrm{NPMx}_{\mathrm{i}} / \mathrm{Pxi} \quad 1$ : berarti penggunaan faktor-faktor produksi tidak efisien, untuk mencapai efisiensi input $\mathrm{X}$ dikurangi.

\section{HASIL DAN PEMBAHASAN}

Hasil pendugaan persamaan regresi linear berganda (double logaritma natural/ln) yang diolah menggunakan program Statistical Product and Servise Solution(SPSS) versi 18, fungsi produksi usahatani lidah buaya seperti tertera pada Tabel 1. berikut ini.

Tabel 1. Hasil Analisis Regresi Fungsi Produksi Cobb-Douglas Pada Usahatani Lidah Buaya di Kota Pontianak 2013.

\begin{tabular}{lccc}
\hline Model Regresi & Koefisien Regresi & t-hitung & Signifikasi \\
\hline Konstanta & 3,715 & 9,696 &, 000 \\
$\operatorname{Bibit}\left(\mathrm{X}_{1}\right)$ & 0,412 & 4,709 &, 000 \\
$\operatorname{Urea}\left(\mathrm{X}_{2}\right)$ & 0,281 & 3,148 &, 003 \\
$\mathrm{Abu}\left(\mathrm{X}_{3}\right)$ & 0,176 & 2,546 &, 015 \\
Tenaga Kerja HOK $\left(\mathrm{X}_{4}\right)$ & 0,097 & 1,033 &, 308 \\
\hline
\end{tabular}

Constant returns to scale $\quad 0,966$

$\mathrm{R}$-sq $=94,4 \% \quad$ F hitung $=155.394 \quad$ Sig $=, 000^{\mathrm{a}}$

Sumber : Analisis data primer 2013

Berdasarkan hasil analisis fungsi produksi Cobb-Douglas (Tabel. 1) bahwa 94.4 persen produksi usahatani lidah buaya dapat dijelaskan oleh adanya variasi variabel independen faktor produksi (bibit, abu, pupuk urea, dan tenaga kerja). Sedangkan 5.6 persen diterangkan oleh variabel lain di luar model seperti dijelaskan dalam metode analisis. Semua variabel independen faktor produksi yaitu bibit, abu, pupuk urea dan tenaga kerja, secara bersama-sama memberikan pengaruh yang signifikan terhadap produksi usahatani lidah buaya.

Selanjutnya dari hasil analisis regresi fungsi produksi Cobb-Douglas pada tabel diatas diperoleh persamaan model Cobb-Douglas untuk usahatani lidah buaya di Kota Pontianak seperti berikut :

$\operatorname{Ln} Y=3,715+0,412 \operatorname{Ln} X_{1}+0,281 \operatorname{Ln} X_{2}+0,176 \operatorname{Ln} X_{3}+0,097 \operatorname{Ln} X_{4}$ sehingga :

$\mathbf{Y}=3,715 \cdot \mathbf{X}_{1}{ }^{0,412} \cdot \mathbf{X}_{2}{ }^{0,281} \cdot \mathbf{X}_{3}^{0,176} \cdot \mathbf{X}_{4}^{0,097}$

Untuk melihat bagai mana akibat penambahan satu satuan input terhadap output dapat dilihat pada table 2 berikut ini: 
Tabel 2. Penambahan Output Akibat Penambahan Satu Satuan Input Pada Usahatani Lidah Buaya di Kota Pontianak.

\begin{tabular}{lccrc}
\hline Faktor Produksi & bi & Y & \multicolumn{1}{c}{ Xi } & Penambahan Y \\
\hline Bibit $\left(\mathrm{X}_{1}\right)$ & 0,412 & 104683,33 & 5829,167 & 7,40 \\
$\operatorname{Abu}\left(\mathrm{X}_{2}\right)$ & 0,281 & 104683,33 & 14438,100 & 2,04 \\
Urea $\left(\mathrm{X}_{3}\right)$ & 0,176 & 104683,33 & 348,333 & 52,89 \\
Tenaga & 0,097 & 104683,33 & 306,309 & 33,15 \\
Kerja/HOK $\left(\mathrm{X}_{4}\right)$ & & & &
\end{tabular}

Sumber : Analisis data primer 2013

Variabel faktor produksi bibit, abu, urea dan tenaga kerja berpengaruh positif sangat nyata terhadap produksi usahatani lidah buaya. Setiap penambahan masing-masing satu persen bibit, abu, urea dan tenaga kerja akan memberikan tambahan produksi usahatani lidah buaya berturut-turut sebesar 0,412 persen, atau setiap penambahan 1 batang bibit akan meningkatkan produksi sebesar 7,40 $\mathrm{Kg}$ untuk bibit, sebesar 0,281 persen, atau setiap penambahan 1 kilogram abu akan meningkatkan produksi lidah buaya sebesar 2,04 kilogram untuk abu, sebesar 0,176 persen atau jika dilakukan pemberian 1 kilogram pupuk urea akan memberikan tambahan produksi sebesar 52,89 kilogram untuk urea dan penambahan 1 HOK tenaga kerja akan meningkatkan produksi lidah buaya sebesar 0,097 persen atau penambahan $33,15 \mathrm{Kg}$ untuk HOK tenaga kerja.

Efisiensi alokasi penggunaan faktor faktor produksi usahatani lidah buaya dianalisis menggunakan uji efisiensi harga atau efisiensi alokatif dengan menggunakan ratio nilai produk marjinal sama dengan harga input yaitu: NPMxi/Pxi $=1$ = ki. Uji efisiensi harga ini dapat digunakan untuk menyatakan apakah petani rasional atau tidak dalam menjalankan kegiatan usahataninya. Hasil analisis efisiensi alokasi penggunaan factor-faktor produksi(bibit, abu, urea dan tenaga kerja) dapat di lihat pada tabel 3.

Tabel 3. Hasil Perhitungan Efisiensi Alokasi Penggunaan Faktor Produksi Usahatani Lidah Buaya di Kota Pontianak 2013

\begin{tabular}{|c|c|c|c|c|c|c|c|}
\hline $\begin{array}{l}\text { Faktor } \\
\text { Produksi }\end{array}$ & bi & Yi & $\mathrm{P}_{\mathrm{Yi}}$ & $\mathrm{Xi}$ & Pxi & NPMxi & $\begin{array}{c}\mathrm{NPM} / \mathrm{Pxi} \\
(\mathrm{ki})\end{array}$ \\
\hline $\operatorname{Bibit}\left(\mathrm{X}_{1}\right)$ & 0,412 & 104683,33 & 1700 & 5829,167 & 1.000 & 12578,16 & 12,58 \\
\hline $\mathrm{Abu}\left(\mathrm{X}_{2}\right)$ & 0,281 & 104683,33 & 1700 & 14438,100 & 500 & 3463,56 & 6,93 \\
\hline $\operatorname{Urea}\left(\mathrm{X}_{3}\right)$ & 0,176 & 104683,33 & 1700 & 348,333 & 2.500 & 89917,56 & 35,96 \\
\hline T.K/HOK $\left(\mathrm{X}_{4}\right)$ & 0,097 & 104683,33 & 1700 & 306,309 & 100.000 & 56355,78 & 0,56 \\
\hline
\end{tabular}

Sumber : Analis data primer 2013

Keterangan :

$$
\begin{aligned}
\mathrm{bi} & =\text { elastisitas produksi } \\
\mathrm{Yi} & =\text { output rata-rata } \\
\mathrm{PY} & =\text { harga output } \\
\mathrm{Xi} & =\text { input } \\
\mathrm{Pxi} & =\text { harga input } \\
\mathrm{NPM} & =\text { nilai produk marjinal } \\
\mathrm{ki} & =\text { efisiensi alokasi/harga }
\end{aligned}
$$


Hasil analisis efisiensi alokatif pada table 3, menunjukan bahwa faktor bibit, abu dan urea dalam penggunaannya oleh petani lidah buaya di Kota Pontianak belum efisien, sedangkan faktor tenaga kerja tidak efisien. Oleh sebab itu penambahan bibit, abu dan urea masih dapat dilakukan hingga pada taraf efisiensi yang optimal agar produksi dapat dioptimalkan pula. Adapun faktor tenaga kerja sudah tidak efisien dan secara ideal harus dikurangi, namun tidak efisiennya faktor tenaga kerja ini bukan disebabkan oleh jumlah HOK yang banyak, tetapi dipengaruhi oleh harga HOK yang tinggi yaitu Rp 100.000,-.

\section{KESIMPULAN DAN SARAN}

\section{Kesimpulan}

1. Penggunaan faktor-faktor produksi bibit, abu dan urea pada usahatani lidah buaya di sentra produksi Kecamatan Pontianak Utara Kota Pontianak belum efisien secara alokatif sehingga perlu penambahan jumlah pada masing-maing input tersebut, sedangkan faktor produksi tenaga kerja secara alokatif tidak efisien sehingga perlu pengurangan jumlah tenaga kerja sesuai dengan kemampuan usahatani dalam membayar upah hari orang kerja.

2. Secara simultan (Uji-F), faktor produksi (bibit, abu, pupuk urea dan tenaga kerja berpengaruh sangat nyata terhadap produksi usahatani lidah buaya.

3. Secara Parsial (Uji-t), input variabel faktor produksi (bibit, abu, pupuk urea, tenaga kerja berpengaruh (sangat nyata) terhadap produksi usahatani lidah buaya.

4. Hasil analisis ekonomi bermanfaat sebagai pertimbangan dalam memperbaiki sistem agribisnis lidah buaya di Kota Pontianak agar menguntungkan.

\section{Saran}

1. Penggunaan tenaga kerja dari lingkungan keluarga sebaiknya tetap dipertahankan, dan kualitas tenaga kerja perlu ditingkatkan dengan mengikuti pelatihan.

2. Penggunaan faktor produksi (bibit, abu, pupuk urea, tenaga kerja kerja) harus dilakukan secara efektif dan efisien.

3. Penggunan bibit sebaiknya dari tanaman sendiri, namun bibit yang akan ditanam terlebih dahulu dilakukan seleksi dan diberikan perlakuan yang dapat meningkatkan produksi

4. Sebagai salah satu komoditas unggulan Kalimantan Barat tanaman lidah buaya perlu dipertahankan dan terus dipromosikan.

5. Pemerintah Provinsi Kalimantan Barat perlu mempromosikan tanaman lidah buaya dengan gerakan membudayakan kepada masyarakat untuk minum produk lidah buaya setiap hari atau setiap ada kegiatan yang melibatkan masyarakat ramai.

6. Pemerintah Provinsi Kalimantan Barat dan jajarannya dapat mewajibkan kepada setiap penyelenggara kegiatan seperti seminar-seminar, pertemuan ilmiah dan lain-lain, supaya selalu menghidangkan minuman lidah buaya dan mempromosikannya dengan membuat selogan-selogan disamping hidangan lainnya. 


\section{DAFTAR PUSTAKA}

Ahdhiana, 2005. Analisis Efisiensi Ekonomi Usahatani Lidah Buaya (Aloe vera) di Kabupaten Bogor: Pendekatan Stochastic Production Frontier. Tesis Sekolah Pascasarjana Institut Pertanian Bogor.

Ahmad, S, M.A, Kalhoro, Z. Kalpadia, Y. Badar, 2003. Aloe a Biologicalli Active And Potential Medicinal Plant. Hamdarrd Medicus. Quarterly Journal of Sci and Med. Vol XXXVI. No 1

Anonimous. 2010a. Budidaya Tanaman Lidah Buaya. Disimpan dalam Uncategorized. . www.agroekonomi.com. Diakses 28 Juli, 2010.

-----------. 2010b. Dukungan Kebijakan Pemerintah Provinsi Kalimantan Barat Dalam Pengembangan Investasi dan Infra Struktur Di Wilayah Kapet Khatulistiwa. Bappeda Provinsi Kalimantan Barat dalam rangka Workshop dan Presentasi Bisnis Kapet Khatulistiwa, 25 Oktober 2010.

- 2004. Map of Peatland Distribution Area And Carbon Content in Kalimantan. Weatlands International-Indonesia Programme. First Edition.

Gubernur Propinsi Kalimantan Barat. 2002. Surat Keputusan Nomor 505 Tahun 2002, Tentang Penetapan Komoditi Unggulan Daerah Kalimantan Barat. Pontianak 2002.

Iskandar. 2008. Metode Penelitian Pendidikan dan Sosial (Kualitatif dan Kuantitatif). Gaung Persada Press. Jakarta.

Soekartawi. 2003. Agribisnis Teori dan Aplikasinya. PT Raja Grafindo Persada. Cetakan ke 7. 2003

-----------.2002. Analisis Usahatani. Universitas Indonesia Press. Jakarta . 1994. Teori Ekonomi Produksi Dengan Pokok Bahasan Analisis Fungsi Produksi Cobb-Douglas. Rajawali Jakarta.

------------. 1991. Dasar Dasar Penyusunan Evaluasi Proyek. CV. Rajawali. Jakarta. 